\title{
Keggin heteropolycompounds as catalysts for liquid-phase oxidation of sulfides to sulfoxides/sulfones by hydrogen peroxide
}

\author{
Gustavo P. Romanelli a, Paula I. Villabrille ${ }^{\mathrm{a}, *}$, Cármen V. Cáceres ${ }^{a}$, Patricia G. Vázquez a , Pietro Tundo b,c \\ a Centro de Investigación y Desarrollo en Ciencias Aplicadas "Dr. Jorge J. Ronco" (CINDECA) CCT-LaPlata-CONICET, Facultad de Ciencias Exactas, Universidad Nacional de La Plata, \\ Calle 47 No. 257 (B1900AJK) La Plata, Argentina \\ b Dipartamento di Scienze Ambientali, Universitá Ca'Foscari, Venice, Italy \\ c Consorzio Interuniversitario Nazionale La Chimica per l'Ambiente, Venice, Italy
}

\section{A R T I C L E I N F O}

\section{Article history:}

Received 22 October 2010

Received in revised form 14 December 2010

Accepted 16 December 2010

Available online 23 December 2010

\section{Keywords:}

Sulfide oxidation

Hydrogen peroxide

Keggin-type molybdovanadophosphoric acids

Keggin-type molybdovanadophosphate

pyridinium salt

\begin{abstract}
A B S T R A C T
$\mathrm{H}_{4} \mathrm{PMo}_{11} \mathrm{VO}_{40}, \mathrm{H}_{5} \mathrm{PMo}_{10} \mathrm{~V}_{2} \mathrm{O}_{40}$ and $\mathrm{H}_{9} \mathrm{PMo}_{6} \mathrm{~V}_{6} \mathrm{O}_{40}$ acids and an acidic pyridinium salt of $\mathrm{H}_{4} \mathrm{PMo}_{11} \mathrm{VO}_{40}$ were synthesized. They were characterized by FT-IR and the variations of their acid properties were determined by titration with $n$-butylamine. They proved to be highly active and selective catalysts for the hydrogen peroxide oxidation of methyl phenyl sulfide to the corresponding sulfoxide or sulfone. The conversion and selectivity results may be explained in terms of the co-existence of acidic and oxidative properties in the catalysts. On the other hand, a convenient catalytic homogeneous procedure has been found to oxidize different sulfides to sulfoxides or sulfones, with $35 \%$ aqueous $\mathrm{H}_{2} \mathrm{O}_{2}$, using $(\mathrm{PyH}) \mathrm{H}_{3} \mathrm{PMo}_{11} \mathrm{VO}_{40}$ as catalyst. The oxidation reaction is carried out at room temperature for sulfoxides or $40{ }^{\circ} \mathrm{C}$ for sulfones and requires a short time. The sulfoxides or sulfones were obtained with excellent yields by controlling the amount of $\mathrm{H}_{2} \mathrm{O}_{2}$.
\end{abstract}

(c) 2010 Elsevier B.V. All rights reserved.

\section{Introduction}

Sulfoxides and sulfones are important intermediates in organic chemistry due to their application in fundamental research and other extended usage, especially because chiral sulfoxides are versatile intermediates for the preparation of biologically and medically important products [1]. Omeprazole and the pesticide Fipronil are two typical examples of the extensive application of these intermediates in pharmaceutical and fine chemical industries [2]. The most widely used method for the preparation of sulfoxides and sulfones is the oxidation of the corresponding sulfide. For this reason, sulfide oxidation to sulfoxides and sulfones has been the subject of many studies, and several methods for this transformation have been reported in the literature [3-8]. Some traditional oxidizing reagents used for this purpose include nitric acid, trifluoroperacetic acid, hydrogen peroxide, nitromethane solution in dilute $\mathrm{NO}_{3} \mathrm{H} / \mathrm{H}_{2} \mathrm{SO}_{4}$, iodic acid, other hypervalent iodine reagents, and CAN (cerium ammonium nitrate), among others [1,8-11].

On the other hand, the introduction of a catalytic method to synthesize aliphatic and aromatic sulfoxides is still needed. The catalytic conversion has been accomplished using reagents such as binuclear manganese complexes periodic acid, $\mathrm{N}$-hydroxyphthalimide-molecular oxygen, sodium perborate and/or sodium percarbonate and silica

\footnotetext{
* Corresponding author. Tel.: +54 221421 1353/425 4277; fax: +54 2214254277 E-mail address: paulav@conicet.gov.ar (P.I. Villabrille).
}

sulfuric acid in the presence of $\mathrm{KBr}$, manganese(III) complexes with bidentate $\mathrm{O}, \mathrm{N}$-donor oxazoline ligand and UHP oxidizing agent, supported nitric acid on silica gel and polyvinylpyrrolidone (PVP) catalyzed by $\mathrm{KBr}$ and/or $\mathrm{NaBr}$ [12-17]. However, some of these methods have drawbacks such as the use of corrosive acids, hazardous peracids and toxic metallic compounds that generate waste streams. Consequently, it is necessary to develop environmentally benign methods.

In the last decades, very useful procedures involving catalysis and hydrogen peroxide, as oxidant, have been developed. They promote the oxidation of organic substrates due to their effective oxygen content, low cost, safety in storage and operation and, mainly, the environmentally friendly character of hydrogen peroxide. These obvious advantages have encouraged the development of useful procedures for hydrogen peroxide oxidation of sulfides, including the use of a wide range of catalysts based on metal or semimetals, for example the previously mentioned binuclear manganese complex [18] or heteropolyacids [19,20].

Heteropolyacids (HPA) with Keggin structures show activity as both acid and redox catalysts. Keggin structures are interesting catalysts; due to their complex structure and reactive properties they give ample opportunity for novel scientific study [21-23].

Keggin vanadium-based structures have also been reported [24]. More typical than pure vanadium-addenda complexes are the mixed addenda complexes of molybdenum and/or tungsten, in which one to three of the addenda are replaced by vanadia. They could be either electron oxidants or strong acids, with an acid strength higher than that of the classical acids. 


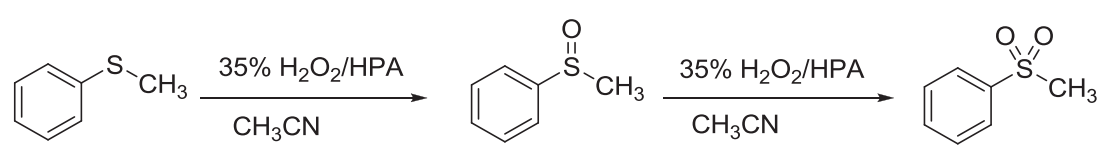

Scheme 1. Oxidation of methyl phenyl sulfide catalized by HPA to methyl phenyl sulfoxide or to methyl phenyl sulfone.

These vanadium heteropolycompounds have recently been studied due to their importance as catalysts in the oxidation reaction, for example, hydroxylation of benzene, oxidation of toluene, nitrobenzene and norbornene using aqueous hydrogen peroxide [25], benzyl alcohol oxidation [26], oxidation of benzoins to benzyls, aldehydes and esters by dioxygen [27], and liquid-phase oxidation of methane with hydrogen peroxide [28]. Recently Leng and co-workers [29] reported the use of pyridine modified molybdovanadophosphate hybrid catalyst for the direct hydroxylation of benzene by hydrogen peroxide in the acetic acid and acetonitrile mixed solvent.

The objective of the present work is to investigate the influence of Keggin-type molybdovanadophosphoric acids and their acidic pyridine salt on the selective homogeneous oxidation of sulfides with aqueous hydrogen peroxide, at room temperature for sulfoxides and $40{ }^{\circ} \mathrm{C}$ for sulfones.

\section{Experimental}

\subsection{Catalyst preparation}

The heteropolyacids $\mathrm{H}_{4} \mathrm{PMo}_{11} \mathrm{VO}_{40}$ (M11PV1), $\mathrm{H}_{5} \mathrm{PMo}_{10} \mathrm{~V}_{2} \mathrm{O}_{40}$ (M10PV2) and $\mathrm{H}_{9} \mathrm{PMo}_{6} \mathrm{~V}_{6} \mathrm{O}_{40}$ (M6PV6) were prepared by a hydrothermal synthesis method [24]. As example is presented M11PV1 synthesis according to the next procedure: a stoichiometric mixture of $0.98 \mathrm{~g}$ of phosphoric acid, $0.91 \mathrm{~g}$ of vanadium pentoxide and $14.4 \mathrm{~g}$ of molydenum trioxide was suspended in $150 \mathrm{~mL}$ of distilled water. The mixture was stirred for $6 \mathrm{~h}$ at $80^{\circ} \mathrm{C}$. After cooling down to $20^{\circ} \mathrm{C}$ and removal of insoluble molybdates and vanadates, the heteropolyacid solution was evaporated and dried at $85^{\circ} \mathrm{C}$ for $24 \mathrm{~h}$. After that, orange crystals of M11PV1A were obtained.

A mixed proton-pyridinium salt, containing one pyridinium cation per heteropolyanion, was prepared from M11PV1, (РyH) $\mathrm{H}_{3} \mathrm{PMo}_{11} \mathrm{VO}_{40}$ (M11PV1Py1) [30]. The determined amount of pyridine was slowly added to an aqueous HPA solution $(5.26 \mathrm{~g}$ in $30 \mathrm{~mL}$ of water) in continuous stirring for $5 \mathrm{~h}$. The mixture was dried at $80{ }^{\circ} \mathrm{C}$ until a precipitate was obtained.

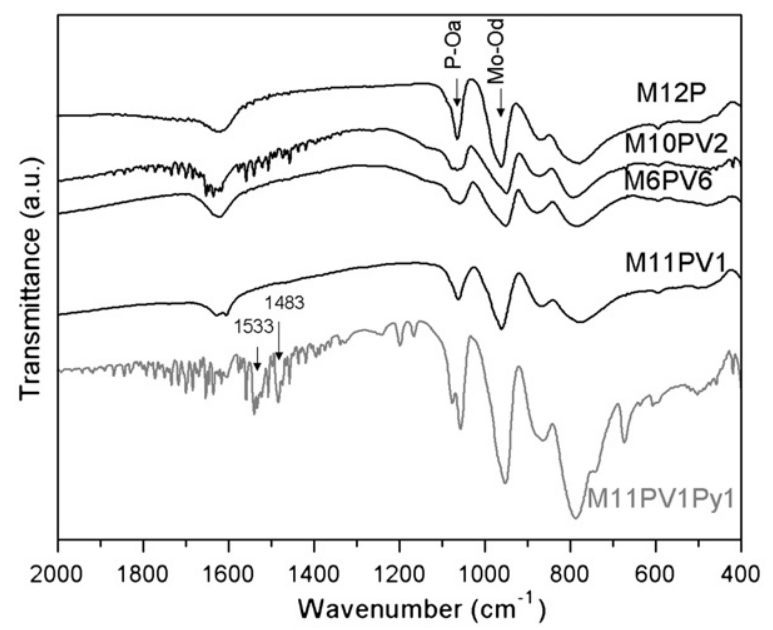

Fig. 1. FT-IR spectra of M12P, M11PV1, M10PV2, and M6PV6 acids and M11PV1Py1 salt.

\subsection{Catalyst characterization}

\subsubsection{Fourier transform infrared spectroscopy (FT-IR)}

Bruker IFS 66 equipment, pellets with BrK, and a measuring range of $400-1500 \mathrm{~cm}^{-1}$ were used to obtain the FT-IR spectra of the solid samples.

\subsubsection{Potentiometric titration}

$0.05 \mathrm{~mL}$ of $0.1 \mathrm{~N} n$-butylamine in acetonitrile was added to a known mass of solid $(0.05 \mathrm{~g})$ using acetonitrile as solvent, and stirred for $3 \mathrm{~h}$. Later, the suspension was titrated with the same base at $0.05 \mathrm{~mL} / \mathrm{min}$. The electrode potential variation was measured with an Instrumentalia S.R.L. digital $\mathrm{pH}$ meter, using a double junction electrode.

\subsection{Catalytic test}

The oxidation of methyl phenyl sulfide to methyl phenyl sulfoxide or methyl phenyl sulfone (Scheme 1) was typically carried out by stirring a solution of $0.7 \mathrm{mmol}$ of the substrate and $0.01 \mathrm{mmol}$ of the catalyst in $5 \mathrm{~mL}$ of acetonitrile, at 20 or $40^{\circ} \mathrm{C}$, respectively. The oxidant used was $\mathrm{H}_{2} \mathrm{O}_{2} 35 \%$ in aqueous solution ( 2 or $20 \mathrm{mmol}$, respectively). The sample was collected from the reaction mixture during the reaction at time intervals. About $20 \mu \mathrm{L}$ of the reaction mixture was taken for each sample, which was then diluted in a mixture of water-dichloromethane $(2 \mathrm{~mL})$. The dichloromethane layer was dried with anhydrous sodium sulfate and filtered. GC/MS analyses were performed on an HP 5971 mass detector coupled to an HP gas chromatograph fitted with a $30 \mathrm{~m} \times 0.25 \mathrm{~mm}$ DB5 capillary column. The percentages of each compound in the reaction mixture were directly estimated from the corresponding chromatographic peak areas. The yield (\%) of pure sulfoxide or sulfone, the turnover number (TON: product mol $\times$ catalyst $\mathrm{mol}^{-1}$ ) and turnover frequency

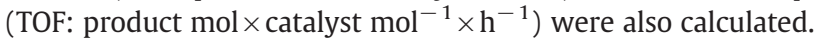

Under these optimum conditions and using M11PV1Py1 as catalyst, different sulfides were oxidized to sulfoxides (for $30 \mathrm{~min}$ ) and to sulfones (for 2.5 and $3.5 \mathrm{~h}$ ) depending on the substrate. The

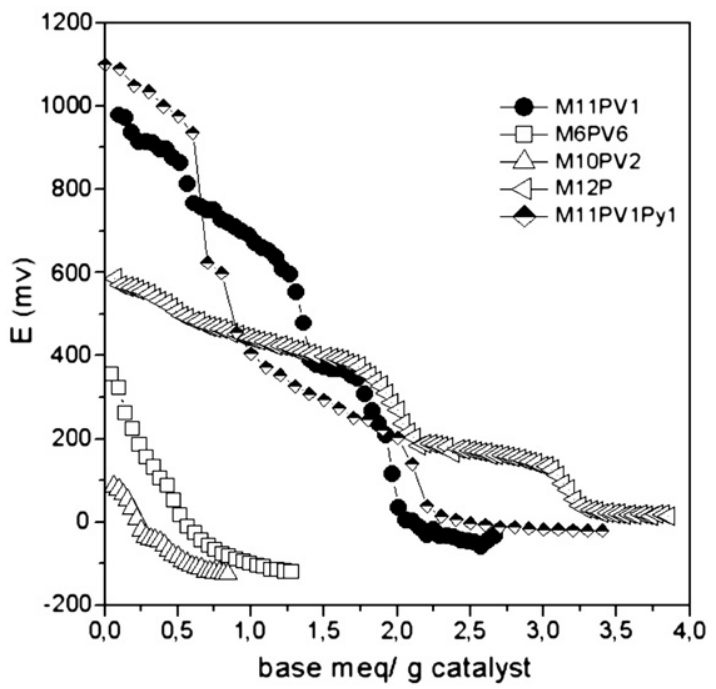

Fig. 2. Potentiometric titration curves for M12P, M11PV1, M10PV2, and M6PV6 acids and M11PV1Py1 salt. 


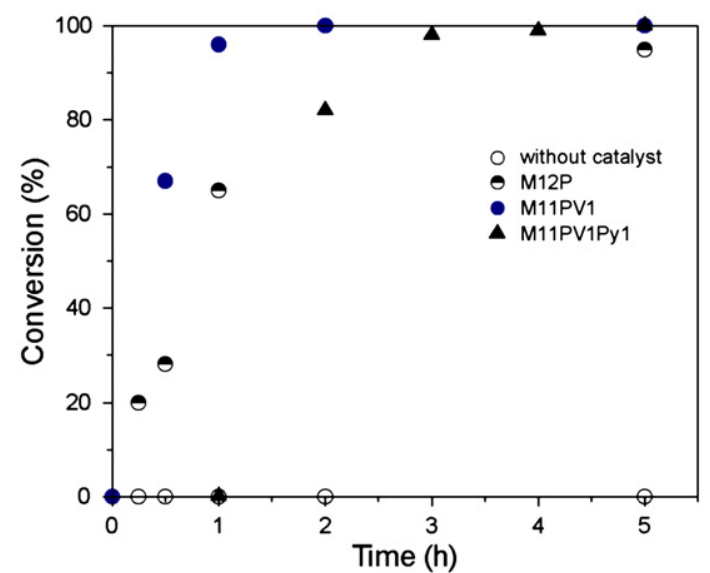

Fig. 3. Conversion vs. reaction time for the oxidation reaction of Scheme 1: without catalyst and with M12P, M11PV1 or M11PV1Py1 as catalysts. Sulfide: $35 \% \mathrm{H}_{2} \mathrm{O}_{2}$ : catalyst $=0.7: 2: 0.01 \mathrm{mmol}$; acetonitrile: $5 \mathrm{~mL}$.

solid sulfoxides or sulfones were purified by recrystallization to afford the pure products.

In a blank experiment, no sulfoxide and sulfone were detected in the absence of the catalyst (for $10 \mathrm{~h}$ ) at room temperature $\left(20^{\circ} \mathrm{C}\right)$ using an excess of hydrogen peroxide $(35 \% \mathrm{w} / \mathrm{v}, 1 \mathrm{~mL}$, relation between diphenylsulfide and hydrogen peroxide $1 / 20$ ) and acetonitrile as solvent.

In addition, we have observed by iodometric titration that less than $5 \%$ of $\mathrm{H}_{2} \mathrm{O}_{2}$ was wasted in decomposition at the end of the reaction (condition: $20{ }^{\circ} \mathrm{C}, 20 \mathrm{mmol}_{2} \mathrm{O}_{2}$ ). The hydrogen peroxide efficiency was more than $95 \%$.

We also performed the oxidation reaction at $20^{\circ} \mathrm{C}$ with substrates sensitive to oxidation. Double and triple bonds, alcohols, amines, aldehydes and esters as styrene, phenyl acetylene, undecene, phenyl allyl ether, 1-decanol, aniline and ethyl acetate were not oxidized when the reaction was carried out at $20^{\circ} \mathrm{C}$ for $10 \mathrm{~h}$, with a substrate: $35 \%$ hydrogen peroxide relation of $1: 20$.

\section{Results and discussion}

\subsection{Characterization of catalysts}

FT-IR spectra of Keggin-type molybdovanadophosphoric acids and M11PV1Py1 pyridinium salt are presented in Fig. 1. The main characteristic features of bulk $\mathrm{H}_{3} \mathrm{PMo}_{12} \mathrm{O}_{40}$ (M12P) in FT-IR [24] are observed at $1064\left(\mathrm{P}-\mathrm{O}_{\mathrm{a}}\right), 964\left(\mathrm{Mo}-\mathrm{O}_{\mathrm{d}}\right), 871\left(\mathrm{Mo}-\mathrm{O}_{\mathrm{b}}-\mathrm{Mo}\right)$ and 784 $\left(\mathrm{Mo}-\mathrm{O}_{\mathrm{c}}-\mathrm{Mo}\right) \mathrm{cm}^{-1}$. The characteristic stretches associated with the Keggin structure of M11PV1 are shown in Fig. 1. In these spectra, a splitting of the $\mathrm{P}-\mathrm{O}_{\mathrm{a}}$ band and a shift of the Mo- $\mathrm{O}_{\mathrm{d}}$ band were observed compared to those of V-free HPA [24]. The M10PV2 and M6PV6 acids show similar behavior. This indicates that indeed $\mathrm{V}$ has been incorporated into the Keggin units. The FT-IR spectra of pyridinium salt (M11PV1Py1) showed those four bands assigned to a Kegginstructure heteropolyacid and a shift of the characteristic bands for pyridinium ion from $1440 \mathrm{~cm}^{-1}$ and $1380 \mathrm{~cm}^{-1}$ to $1533 \mathrm{~cm}^{-1}$ and $1483 \mathrm{~cm}^{-1}$, respectively, in well agreement with a previous report [29]. This behavior indicates that pyridine acts as countercation and it does not incorporated in the Keggin units.

Table 1

Oxidation potential of the heteropolyacids.

\begin{tabular}{ll}
\hline Heteropolycompound & Oxidation potential [31] \\
\hline $\mathrm{H}_{3} \mathrm{PMo}_{12} \mathrm{O}_{40}$ & $+0.52 \mathrm{~V}$ \\
$\mathrm{H}_{4} \mathrm{PMo}_{11} \mathrm{VO}_{40}$ & $+0.65 \mathrm{~V}$ \\
$\mathrm{H}_{5} \mathrm{PMo}_{10} \mathrm{~V}_{2} \mathrm{O}_{40}$ & $+0.70 \mathrm{~V}$ \\
$\mathrm{H}_{9} \mathrm{PMo}_{6} \mathrm{~V}_{6} \mathrm{O}_{40}$ & $+0.77 \mathrm{~V}$ \\
\hline
\end{tabular}

(a)

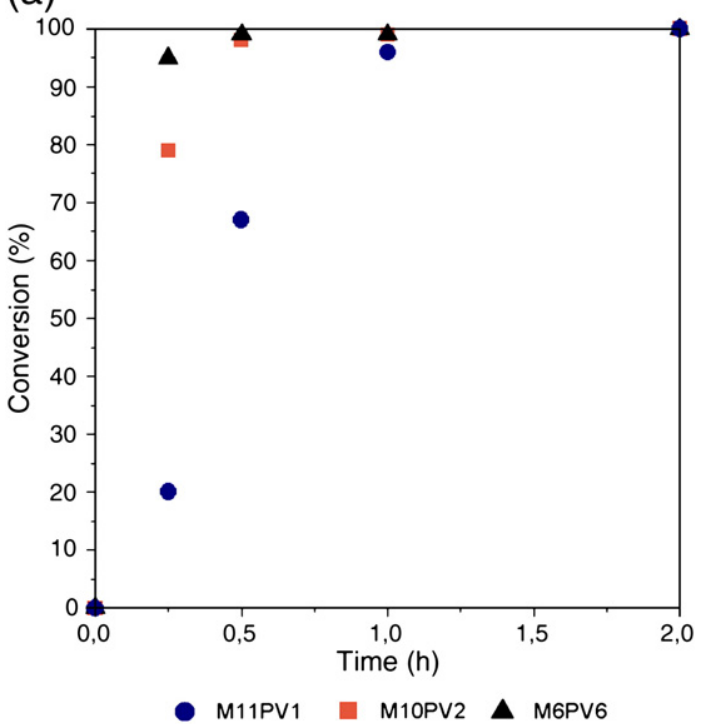

(b)

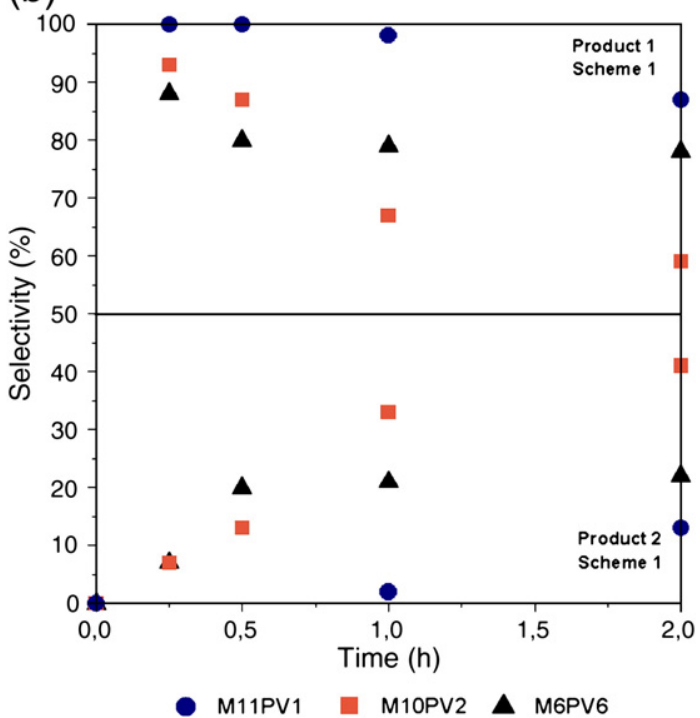

Fig. 4. a) Conversion vs. reaction time for the catalytic oxidation of Scheme 1, using M12-xPVx as catalyst. Sulfide: $35 \% \mathrm{H}_{2} \mathrm{O}_{2}$ : catalyst $=0.7: 2$ : $0.01 \mathrm{mmol}$; acetonitrile: $5 \mathrm{~mL}$. b) Selectivity vs. reaction time for both products of the catalytic oxidation of Scheme 1, using M12-xPVx as catalyst. Sulfide: $35 \% \mathrm{H}_{2} \mathrm{O}_{2}$ : catalyst $=0.7: 2$ : $0.01 \mathrm{mmol}$; acetonitrile: $5 \mathrm{~mL}$.

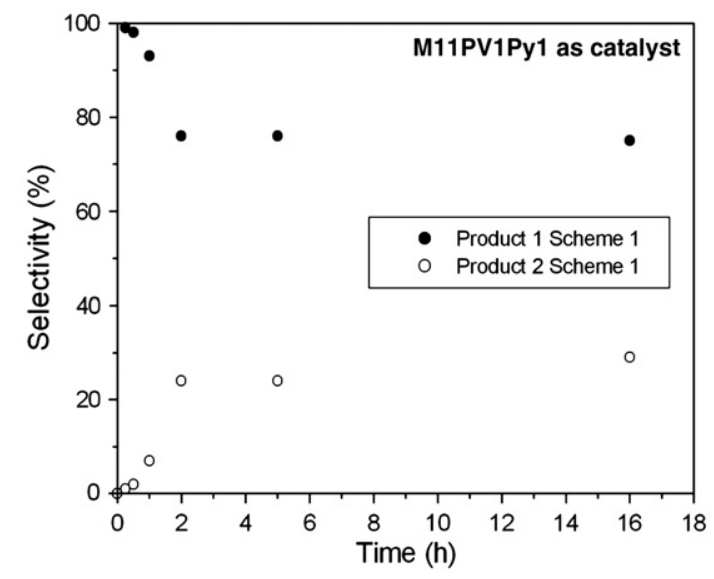

Fig. 5. Selectivity vs. reaction time for both products of the catalytic oxidation of Scheme 1, using M11PV1Py1 as catalyst. Sulfide: $35 \% \mathrm{H}_{2} \mathrm{O}_{2}$ : catalyst $=0.7$ : 2 : $0.01 \mathrm{mmol}$; acetonitrile: $5 \mathrm{~mL}$. 


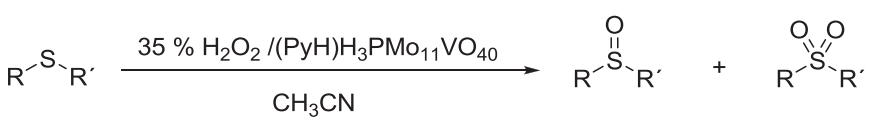

Scheme 2. Selective oxidation of sulfides to sulfoxides or sulfones catalyzed by M11PV1Py1.

In relation to the acidic properties, the HPA present Brönsted acidity. M11PV1 shows very strong sites at $20^{\circ} \mathrm{C}$, with a maximum acid strength, corresponding to an initial electrode potential of $978 \mathrm{mV}$, higher than that obtained for the V-free sample, $600 \mathrm{mV}$ (Fig. 2). The replacement of one $\mathrm{Mo}^{+6}$ by $\mathrm{V}^{+5}$ modifies the Keggin structure as was shown before by FT-IR. There is a weakness of the V$\mathrm{O}_{\mathrm{a}}$ interaction and the protons reside mainly in the bridging water moieties forming $\mathrm{H}_{5} \mathrm{O}_{2}^{+}$. This modification changes the charges of different oxygen atoms of Keggin primary structure, mainly $\mathrm{O}_{\mathrm{b}}$, and could be related to a higher acid strength of a new proton [24]. In the case of M10PV2 and M6PV6 acids, the acid strength decreased to 400 and $100 \mathrm{mV}$ (Fig. 2). When the number of $\mathrm{V}$ atoms increases, the charge of the anion is higher. Consequently, the anion-proton interaction increases and the acidity of the compounds decreases.

When M11PV1 was transformed into the hybrid material (M11PV1Py1), the acid strength increased from 978 to $1100 \mathrm{mV}$, and the potentiometric titration curve was very similar to that of the corresponding HPA.

\subsection{Catalytic activity}

Catalytic oxidation of methyl phenyl sulfide (Scheme 1) was selected as a test reaction. The conversion results obtained for the catalytic oxidation reaction are presented in Fig. 3, using M11PV1 and $\mathrm{M} 12 \mathrm{P}$ as catalysts. In addition, the reaction medium without catalysts

Table 2

Selective oxidation of sulfides to sulfoxides/sulfones catalyzed by M11PV1Py $1^{\mathrm{a}, \mathrm{b}}$.

\begin{tabular}{|c|c|c|c|c|c|}
\hline Entry & Substrate & Time $(\mathrm{h})$ & Yields Sulfoxide $(\%)^{\mathrm{c}} / \mathrm{TON}^{\mathrm{d}} / \mathrm{TOF}^{\mathrm{e}}$ & Time (h) & Yields Sulfone $(\%)^{\mathrm{c}} / \mathrm{TON}^{\mathrm{d}} \mathrm{TOF}^{\mathrm{e}}$ \\
\hline 1 & & 0.5 & 99/69.3/138.6 & 2.5 & $95 / 66.5 / 26.6$ \\
\hline 2 & & 0.5 & $95 / 66.5 / 133$ & 2.5 & $94 / 65 / 26$ \\
\hline 3 & & 0.5 & $94 / 65.8 / 131.6$ & 2.5 & $88 / 61.6 / 24.6$ \\
\hline 4 & & 0.5 & $97 / 67.9 / 135.8$ & 3.5 & $96 / 67.2 / 19.2$ \\
\hline 5 & & 0.5 & $93 / 65.1 / 130.2$ & 3.5 & $93 / 65.1 / 18.6$ \\
\hline 6 & & 0.5 & $91 / 63.7 / 127.4$ & 3 & $89 / 62.3 / 20.8$ \\
\hline $7^{f}$ & & 0.5 & $94 / 65.8 / 131.6$ & 3.5 & 91/63.7/18.6 \\
\hline $8^{\mathrm{f}}$ & & 0.5 & $91 / 63.7 / 127.4$ & 3.5 & $93 / 65.1 / 18.6$ \\
\hline $9^{f}$ & & 0.5 & $91 / 63.7 / 127.4$ & 3.5 & $84 / 58.8 / 16.8$ \\
\hline 10 & & 0.75 & $91 / 63.7 / 84.9$ & 4 & $94 / 65.8 / 16.5$ \\
\hline $11^{\mathrm{g}}$ & & 0.5 & $95 / 66.5 / 133$ & 2.5 & $92 / 64.4 / 25.8$ \\
\hline
\end{tabular}

a Reaction conditions for the selective oxidation of sulfides to sulfoxides: sulfide: $35 \% \mathrm{H}_{2} \mathrm{O}_{2}$ : catalyst $=0.7: 2$ : $0.01 \mathrm{mmol}$; acetonitrile: $5 \mathrm{~mL}$, $20{ }^{\circ} \mathrm{C}$.

b Reaction conditions for the selective oxidation of sulfides to sulfones: sulfide: $35 \% \mathrm{H}_{2} \mathrm{O}_{2}$ : catalyst $=0.7: 20$ : $0.01 \mathrm{mmol}$; acetonitrile: $5 \mathrm{~mL}$; $40{ }^{\circ} \mathrm{C}$.

c Yield (\%) of pure sulfoxide or sulfone.

d $\mathrm{TON}$ (product mol $\times$ catalyst $\mathrm{mol}^{-1}$ ).

e TOF (product mol $\times$ catalyst $\mathrm{mol}^{-1} \times \mathrm{h}^{-1}$ ).

${ }^{f}$ Sulfide was selectively oxidized in the presence of formyl, hydroxyl and double bound groups.

${ }^{g}$ In a stoichiometric mixture of belzaldehyde and methyl phenyl sulfide, sulfide was selectively oxidized in the presence of formyl group. 
was tested and is shown in Fig. 3. Under these experimental conditions, M11PV1 and M12P are dissolved in the solvent used. We have observed that heteropolycompounds used as catalysts in this reaction show acidity as well as oxidizing ability. The highest conversion was obtained for the catalyst with one $\mathrm{V}$ atom in the Keggin-type primary structure. The oxidation potential of this heteropolyacid is higher than the one corresponding to M12P (Table 1 [31]). On the other hand, the activity is very low with nonacid catalysts. Conversion increases when the acid strength of the catalysts (determined by potentiometric titration) increases (Fig. 2). The reactivity of Keggin-type heteropolycompounds is governed by their electronic structure. The addenda atoms (Mo in our case) accept electron density from the terminal oxygen atoms via $\mathrm{p} \pi-\mathrm{d} \pi$ interactions. This effect renders terminal oxygen atoms acidic. In relation to $\mathrm{H}_{2} \mathrm{O}_{2}$, this is a viable oxidizing agent of moderate reactivity at $20^{\circ} \mathrm{C}$. Some form of activation of the $\mathrm{O}-\mathrm{O}$ bond such as a carbonyl group in a peroxy acid or metal catalysis is often employed in order to increase its efficacy as an oxidizing agent [32].

M11PV1, M10PV2 and M6PV6 catalysts were tested under experimental conditions previously used and the conversion results are shown in Fig. 4a. The selectivity for all cases is presented in Fig. 4b, according to Scheme 1 for Products 1 and 2. In homogeneous conditions, for all catalysts used high conversion, to methyl phenyl sulfoxide (Product 1) and methyl phenyl sulfone (Product 2) was obtained. Total conversion was achieved after $1 \mathrm{~h}$ of reaction. Comparing the three V-HPA used, M11PV1 was the most selective to Product 1 (Fig. 4b), this was practically the only oxidation product during the first hour of reaction. However, when the number of $\mathrm{V}$ atoms per Keggin unit increases, the conversion increases as shown in Fig. 4a. On the other hand, M10PV2 and M6PV6 were more selective to Product 2 . These results may be explained in terms of the co-existence of acidic and oxidative properties in the catalysts. The catalysts with lower acidity but with higher redox potential quickly oxidize Product 1 to Product 2. This shows that the oxidation mechanism is that pointed out in Scheme 1 where the conversion to sulfone is increased by the catalysts with higher number of vanadium atoms per Keggin unit, which have higher redox potential.

The conversion results of pyridinium salt from M11PV1 are shown in Fig. 3, and the selectivity to Products 1 and 2 in Fig. 5. The highest conversion and selectivity to methyl phenyl sulfoxide were obtained when M11PV1Py1 was used as catalyst, a behavior that could be explained by the combination of HPA properties with pyridine. According to previous theoretical and computational studies [33], the $\mathrm{V}$ atom is in the primary structure of the classical Keggin-type as a V$\mathrm{OH}$ group, and it lowers its average oxidation state when present as $\mathrm{VO}^{-} \mathrm{PyH}^{+}$species. In addition, it is proposed that the organic $\pi$ electrons may extend their conjugation to the inorganic framework and thus modify the redox properties of the cluster [34,35]. IR spectra in Fig. 1 also suggest this interaction for the present catalyst.

For an oxidation catalyst system for Scheme 1 reactions, high catalytic efficiency and selectivity remain an important goal. We explored the general applicability of these catalysts for the selective oxidation of sulfide to sulfoxides or sulfones. Various functionalized sulfides were reacted according to this oxidation procedure (Scheme 2, Table 2). M11PV1Py1 was used as catalyst in those cases due to its promotion effect on the studied reaction (Scheme 1). All the reactions were completed within a short time and the sulfoxides or sulfones were obtained with excellent yields, as a practically unique oxidation product (Table 2 ).

\section{Conclusions}

The substituted vanadium atoms in Keggin-structure heteropolyacids are essentially active sites with high performance for the oxidation of sulfides to sulfoxides/sulfones. High conversion (100\%) within a very short time was observed using molybdovanadophosphate heteropolycompounds, $\mathrm{H}_{4} \mathrm{PMo}_{11} \mathrm{VO}_{40}, \mathrm{H}_{5} \mathrm{PMo}_{10} \mathrm{~V}_{2} \mathrm{O}_{40}$, $\mathrm{H}_{9} \mathrm{PMo}_{6} \mathrm{~V}_{6} \mathrm{O}_{40}$ and $(\mathrm{PyH}) \mathrm{H}_{3} \mathrm{PMo}_{11} \mathrm{VO}_{40}$, as catalysts in homogeneous conditions. The highest selectivity to sulfoxide was obtained when $(\mathrm{PyH}) \mathrm{H}_{3} \mathrm{PMo}_{11} \mathrm{VO}_{40}$ was used as catalyst.

We have found a clean and convenient procedure for oxidizing sulfides to sulfoxides/sulfones, with $35 \%$ aqueous $\mathrm{H}_{2} \mathrm{O}_{2}$ ( 2 or $20 \mathrm{mmol}$, respectively) and a catalytic amount of pyridinium salt from heteropolyacids. Reagents and catalysts are cheap and easily available. The oxidation reaction is carried out at room temperature for sulfoxides and $40{ }^{\circ} \mathrm{C}$ for sulfones and requires a short time.

\section{Acknowledgments}

The authors thank the INCA, CONICET and UNLP for the financial support and Mrs. G. Valle for their experimental contribution for the measures of FT-IR.

\section{References}

[1] F. Liu, Z. Fu, Y. Liu, Ch. Lu, Y. Wu, F. Xie, Z. Ye, X. Zhon, D. Yin, Ind. Eng. Chem. Res. 49 (2010) 2533-2536, and references cited therein.

[2] M. Rahimizadeh, G. Rajabzadeh, S. Khatami, H. Eshghi, A. Shiri, J. Mol. Catal. A: Chem. 323 (2010) 59-64, and the references cited therein.

[3] A. Khenkin, G. Leitus, R. Neumann, J. Am. Chem. Soc. 132 (2010) 11446-11448.

[4] A. Rostami, J. Akradi, Tetrahedron Lett. 51 (2010) 3501-3503.

[5] A. Rezaeifard, I. Sheikhshoaie, M. Monadi, H. Stoeckli-Evans, Eur. J. Inorg. Chem. 1 (2010) 799-806.

[6] M. Kirihara, J. Yamamoto, T. Noguchi, A. Itou, S. Nato, Y. Hirai, Tetrahedron 65 (2009) 10477-10484.

[7] I. Gamba, S. Palavicini, E. Monzani, L. Casella, Chem. Eur. J. 15 (2009) 12932-12936.

[8] R. Varma, R. Sain, H. Meshram, Tetrahedron Lett. 38 (1997) 6525-6528, and references cited therein.

[9] M. Tajbakhsh, R. Hosseinzadeh, A. Shakoori, Tetrahedron Lett. 45 (2004) 1889-1893, and references cited therein.

[10] M. Lakouraj, M. Tajbakhsh, F. Shirini, M. Asady Tamami, Synth. Commun. 35 (2005) 775-784.

[11] V. Shukla, P. Salgaonkar, K. Akamanchi, J. Org. Chem. 68 (2003) 5422-5425.

[12] D. Barton, W. Li, J. Smith, Tetrahedron Lett. 39 (1998) 7055-7058.

[13] T. Iwahama, S. Sakaguchi, Y. Ishii, Tetrahedron Lett. 39 (1998) 9059-9062

[14] F. Bonadies, F. De Angelis, L. Locati, A. Scettri, Tetrahedron Lett. 37 (1996) 7129-7130.

[15] D. Habibi, M. Zolfigol, M. Safaiee, A. Shamsian, A. Ghorbani-Choghamarani, Catal. Commun. 10 (2009) 1257-1260.

[16] M. Bagherzadeh, R. Latifi, L. Tahsini, M. Amini, Catal. Commun. 10 (2008) 196-200.

[17] M. Zolfigol, K. Amani, A. Ghorbani-Choghamarani, M. Hajiami, R. Ayazi-Nasrabadi, S. Jafari, Catal. Commun. 9 (2008) 1739-1744.

[18] G.B. Shul'pin, G. Süss-Fink, L.S. Shul'pina, J. Mol. Catal. A: Chem. 170 (2001) 17-34.

[19] G. Romanelli, D. Bennardi, V. Palermo, P. Vázquez, P. Tundo, Lett. Org. Chem. 4 (2007) 544-549.

[20] P. Tundo, G. Romanelli, P. Vázquez, F. Aricó, Catal. Commun. 11 (2010) 1181-1184.

[21] M. Misono, Catal. Rev. Sci. Eng. 29 (1987) 269-321.

[22] A. Dolbecq, E. Dumas, C.R. Mayer, P. Mialane, Chem. Rev. 110 (2010) 6009-6048

[23] M.E. Davis, C.J. Dillon, J.H. Holles, J. Labinger, Angew. Chem. Int. Ed. 41 (2002) $858-860$.

[24] P. Villabrille, G. Romanelli, P. Vázquez, C. Cáceres, Appl. Catal., A 270 (2004) $101-111$.

[25] P.S.N. Rao, K.T. Venkateswara Rao, P.S. Sai Prasad, N. Lingaiah, Catal. Commun. 11 (2010) 547-550.

[26] A.S. Kende, F.H. Ebertino, Tetrahedron Lett. 25 (1984) 923-926.

[27] B. El Ali, A.M. El-Ghanam, M. Fettouhi, J. Mol. Catal. A: Chem. 165 (2001) 283-290

[28] Y. Seki, K. Mizuno, M. Misono, Appl. Catal., A 194 (2000) 13-20.

[29] Y. Leng, H. Ge, Ch. Zhou, J. Wang, Chem. Eng. J. 145 (2008) 335-339.

[30] G. Romanelli, P. Vázquez, P. Tundo, Synlett 1 (2005) 75-78.

[31] T. Murtha, US Patent 4507507 (1985).

[32] R.D. Bach, M.D. Su, H.B. Schlegel, J. Am. Chem. Soc. 116 (1994) 5379-5391.

[33] J. Paul, M. Founier, Stud. Surf. Sci. Catal. 130 (2000) 1199-1204.

[34] D. Katsoulis, Chem. Rev. 98 (1998) 359-387.

[35] M. Lu, Y. Wei, B. Xu, C.F.-C. Cheung, Z. Peng, D.R. Powell, Angew. Chem. Int. Ed. 41 (2002) 1566-1568. 